\title{
Sero-prevalence and spatial distribution of Rift Valley fever infection among agro- pastoral and pastoral communities during Interepidemic period in the Serengeti ecosystem, northern Tanzania
}

\author{
Abade Ahmed ${ }^{1 *}$, Jabir Makame ${ }^{1,2}$, Fyumagwa Robert $^{3}$, Keyyu Julius $^{3}$ and Matee Mecky ${ }^{2}$
}

\begin{abstract}
Background: In the past two decades, Rift Valley Fever (RVF) outbreaks have been reported twice in Tanzania, with the most recent outbreak occurring in 2006/07. Given the ecology and climatic factors that support mosquito vectors in the Serengeti ecosystem, we hypothesized a continued transmission of RVF virus (RVFV) during interepidemic periods. This study was carried out to determine sero-prevalence, spatial distribution and factors associated with RVF in at-risk agro-pastoral and pastoral communities in the Serengeti Ecosystem in northern Tanzania.

Methods: A cross sectional study was carried out to establish the general exposure to RVFV by detecting anti-RVFV IgG and anti-RVFV IgM using ELISA techniques. The health facilities where human subjects were blood sampled concurrent with interviews included Bunda District Designated Hospital, Wasso DDH, Endulen hospital, Arash, Malambo, Olbabal, and Piyaya dispenaries (Ngorongoro district) and Nyerere DDH (Serengeti district) respectively. In addition, human subjects from Lamadi ward (Busega district) were recruited while receiving medical service at Bunda DDH. We conducted logistic regression to assess independent risk factor and mapped the hotspot areas for exposure to RVFV.

Results: A total of 751 subjects (males $=41.5 \%$; females $=58.5 \%$ ) with a median age of 35.5 years were enrolled at out-patient clinics. Of them, $34(4.5,95 \% \mathrm{Cl} 3.3-6.3 \%)$ tested positive for anti-RVFV IgG. Of the 34 that tested positive for anti-RVFV IgG, six (17.6\%) tested positive for anti-RVFV IgM. Odds of exposure were higher among pastoral communities (aOR 2.9, 95\% C.I: 1.21-6.89, $p<0.01$ ), and agro-pastoral communities residing in Ngorongoro District (aOR 1.8, 95\% C.I 1.14-3.39, $p=0.03$ ). Hotspot areas for exposure to RVFV were Malambo, Olbalbal and Piyaya wards in Ngorongoro district, and Lamadi ward in Busega district.

Conclusions: The study found both previous and recent exposure of RVFV in humans residing in the Serengeti ecosystem as antibodies against both IgG and IgM were detected. Detection of anti-RVF IgM suggests an ongoing transmission of RVFV in humans during inter-epidemic periods. Residents of Ngorongoro district were most exposed to RVFV compared to Bunda and Serengeti districts. Therefore, the risk of exposure to RVFV was higher among pastoral communities compared to farming communities.
\end{abstract}

Keywords: Rift valley, Serengeti ecosystem, Inter-epidemic human, Tanzania

\footnotetext{
* Correspondence: ahmedabade@yahoo.com

${ }^{1}$ Tanzania Field Epidemiology and Laboratory Training Program, Ministry of

Health, Community Development, Gender, Elderly and Children, P.O Box

71286, Ocean Road, Dar es Salaam, Tanzania

Full list of author information is available at the end of the article
}

(c) The Author(s). 2018 Open Access This article is distributed under the terms of the Creative Commons Attribution 4.0 International License (http://creativecommons.org/licenses/by/4.0/), which permits unrestricted use, distribution, and reproduction in any medium, provided you give appropriate credit to the original author(s) and the source, provide a link to the Creative Commons license, and indicate if changes were made. The Creative Commons Public Domain Dedication waiver (http://creativecommons.org/publicdomain/zero/1.0/) applies to the data made available in this article, unless otherwise stated. 


\section{Background}

Rift Valley Fever (RVF) is a viral zoonotic fever caused by RVF virus (RVFV), a member of the genus Phlebovirus in the family Bunyaviridae [1-3]. It is an illness characterized by deaths and abortion storms primarily in goats, sheep, and cattle [4]. The disease also affects humans, dogs, camels and wildlife [5]. Wild animals such as African buffalo (Syncerus caffer), black rhino (Diceros bicornis), lesser kudu (Tragelaphus imberbis), impala (Aepyceros melampus), kongoni (Alcelaphus buselaphus), monkeys (Cercopithecus spp.), waterbuck (Kobus ellipsiprymnus) and African elephants (Loxodonta africana) have shown to be exposed to the virus $[6,7]$.

Tanzania has experienced 10 epidemic episodes of RVF since 1930s. During the last RVF epidemic a case fatality of $46 \%$ was reported among humans [6-8]. Death of animals due to the disease was estimated to cost around 6 million US dollars, with external market flow dropping by $54 \%$ [8] Shortage of meat and milk probably caused acute malnutrition [9]. Most of the markets were closed and cost of alternative source of protein such as fish and chicken was very high $[9,10]$. In humans, RVFV usually causes mild fever that is often associated with spontaneous recovery $[6,9]$. However, infections characterized by flu-like illness, headache, muscles and joint pain, diarrhoea, vomiting [11] anorexia and high respiratory rate [12] do occur. RVFV may cause serious hepatitis and liver necrosis $[6,7]$ as well as other complications including loss of eyesight, meningo-encephalitis and haemorrhagic fever $[6,13]$. Economically, apart from high livestock loss, the epidemic may affect the tourism industry that contributes over $17 \%$ of GDP in Tanzania [14] because of fear among tourists of contacting the disease from affected wildlife and loss of animal species that are sought for game viewing.

Despite the severity of the RVF, little is known regarding prevalence and exposure status of humans in different ecosystems in Tanzania. Previous studies conducted in Kilombero valley in eastern Tanzania showed high transmission of the disease in livestock, with sero-prevalence of $5.5 \%$ among animals born after last epidemic of 2007 [9]. Correspondingly, current study in the Serengeti ecosystem, which is the sister study to this, has found recent exposure among domestic animals and wildlife. Cattle and sheep recorded IgM prevalence of $5.7 \%$ while buffaloes recorded $3.1 \%$ of IgM prevalence (Nyarobi unpublished). RVFV-RNA was extracted from $2.7 \%$ of mosquitoes pools studied in the ecosystem (Nyarobi unpublished). This has raised need to understand the current disease burden in humans and predict the possibility of future outbreak. Therefore, this study was done to determine the exposure status of RVFV, its spatial distribution and factors associated with exposure to RVFV among pastoral and agro-pastoral communities of the Serengeti ecosystem.

\section{Methods}

\section{Study area and population}

The study was conducted in the Serengeti ecosystem in northern regions of Tanzania. The area included three districts of Bunda, Ngorongoro and Serengeti in the Serengeti ecosystem, (Fig. 1). However, some human subjects were enrolled from Lamadi ward in Busega district. The area is located along the border with Kenya, close to the equator, between 20 to 4 o S. minimum temperature ranges between 15-21oC, while maximum ranges between 24-27oC. The rainfall is highly seasonal with peaks in March to May and November to December. Mean annual rainfall in the Serengeti varies from $1050 \mathrm{~mm}$ in the northwest to $550 \mathrm{~mm}$ in the southeast. The area is covered with rich volcanic soil that supports the growth of vegetation. Meshwork of streams of water bodies are found throughout the area. The ecosystem extends to the shores of Lake Victoria in the west, (where Bunda and Busega districts are located), Lake Eyasi in the south and the Great Rift Valley to the east, covering Ngorongoro Conservation Area (NCA) and Loliondo Game Controlled Area (LGCA) in Ngorongoro district. The study also extended to the western side in Serengeti and Bunda districts (Fig. 1). Soil type, grassy plain, temperature and rainfall of the ecosystem favor the endemicity of the disease in the area. The communities surrounding the area are mainly of pastoral and agro-pastoral communities. Pastoral communities are those deriving their income solely by keeping animals like cattle, sheep, goats, donkey and dogs. Agro-pastoral communities are those depending on crop cultivation supplemented with animal keeping mostly in small scale.

\section{Study design and setting}

A cross-sectional, health facility based study was conducted on humans in the Serengeti ecosystem during the dry season of August-October, 2014. The health facilities where the study were conducted included Wasso District Designated Hospital (DDH), Endulen hospital, Malambo, Piyaya, Arash and Olbabal dispensaries in Ngorongoro District; Bunda DDH in Bunda district and Nyerere DDH in Serengeti district respectively. As a hospital-based study, participants from Lamadi ward (Busega district) bordering Bunda district were also enrolled as they were frequently seeking medical services at Bunda DDH. We enrolled patients aged 5 years and above attending outpatient department (OPD) regardless of their clinical presentation. Patients who could not give assent or consent and those who were critically ill to give information were excluded from the study. A total of 751 human subjects were included in the study. Probability proportion to population size was used to allocate the calculated sample size to the three districts' health facilities. The three districts of Ngorongoro, Serengeti and 


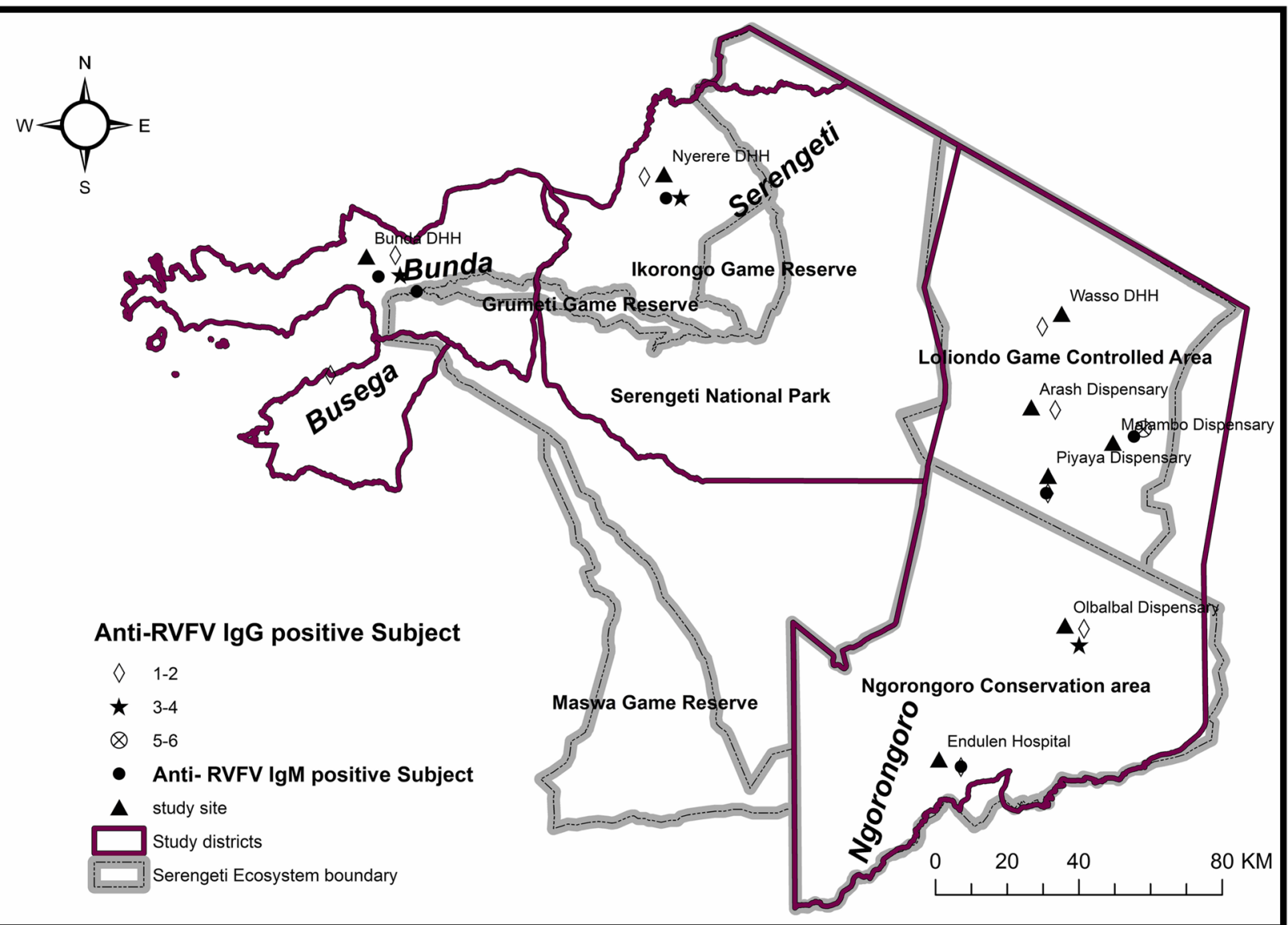

Fig. 1 Map of Serengeti ecosystem showing districts where anti RVF IgG seropositive humans were identified (see attached document)

Bunda districts were allocated 210, 241 and 300 study respondents respectively. Based on geographical nature and sparse population distribution of Ngorongoro district, apart from district hospital, more health facilities were included in the study to allow wider coverage of all parts of the district as much as possible. The additional health facilities were Endulen hospital, as well as Malambo, Piyaya, Arash, and Olbalbal dispensaries. These are the main health facilities in the area that provide services to all population in the study area. Simple random sampling technique was used to select participants among out-patients who visited the respective health facility for medical services or individuals who escorted relatives for medical services in the eight health facilities in the three district i.e. six health facilities in Ngorongoro district, one in Bunda and one in Serengeti districts respectively. The coordinates of the study sites were recorded using a Global Positioning System (GPS) device for subsequent use in marking the sampling sites and indicate locations with sero-positive human subjects in the study area. In Tanzania, the mean straight-line distance to a health facility is about $4.2 \mathrm{~km}(\mathrm{SD} 3.9 \mathrm{~km})$ [15].

\section{Laboratory investigation}

Approximately, $4 \mathrm{mls}$ of whole human blood was drawn aseptically from each patient recruited in the study. Approximately 1-2 mls of sera was obtained from each blood sample through centrifugation, and transferred into screw capped cryovials and stored at $-20{ }^{\circ} \mathrm{C}$ freezer awaiting serological analysis. Sera from patients were tested for the presence of anti-RVFV IgG antibody using competitive Enzyme linked Immuno-sorbent Assay (ID.Vet Innovative Diagnostics, Grabels, France). The test has excellent sensitivity and specificity of $100 \%$. Detection of anti-RVFV IgM was done using capture ELISA kit, to all anti-RVFV IgG positive samples as described by the manufacturer (Biological Diagnostics Supply Limited -BDSL, UK). The sensitivity test was $100 \%$ and specificity ranged from 97.4 to $99.4 \%$ [16]. Validation of the results was done by repeating all positive and $10 \%$ of the negative samples and found $100 \%$ concordance between the first test and observed validation test. 


\section{Data management and statistical analysis}

Information on social demographic characteristics including age, sex, level of education, occupation and area of residence was collected. Median, range, and proportion of seropositive samples among those tested for anti-RVFV IgG (general exposure status) and anti-RVFV IgM (recent exposure status) were calculated. A number of socio-demographic factors associated with RVFV sero-positivity were assessed using prevalence Odds Ratio (OR) as a measure of association at $95 \%$ confidence interval. Socio-demographic factors with $p$-value $\leq 0.05$ were considered as statistically significant in bivariate analysis. All variables with $p \leq 0.2$ at bivariate level were entered into multivariate logistic regression model. Variables with p-value $\leq 0.05$ at multivariate level were considered independently associated with RVF seropositivity.

\section{Results}

A total of 751 participants were enrolled in this study. Their median age was 35.5 years (range $=5-90$ years). Of them, $439(58.5 \%)$ were females, $294(45.9 \%)$ were small scale farmers, 420 (63.8\%) had primary education and 300 (40\%) were from Bunda district (Table 1).

Out of 751 participants tested for anti-RVFV IgG, 34 tested positive making the overall sero-prevalence of $4.5 \%$ (95\% C.I 3.2-6.3\%) (Table 2). Of the 34 positive anti-RVFV IgG subjects, 6 (17.6\%) tested positive for
anti-RVFV IgM. Ngorongoro district recorded high seroprevalence of anti-RVFV antibodies of $8.1 \%$, (17 of 210) compared to $2.1 \%$ recorded in Serengeti district (5 of 241) $(P=0.003)$ (Table 2). The seroprevalence of RVFV was significantly higher among pastoralists $(8.9 \%, 20$ of 227) compared to agro-pastoralists $(3.4 \%, 10$ of 294$)(p$ = 0.008) (Table 2).

The odds of testing positive were almost 3 times higher among the pastoralists as compared to other occupational groups, which are small scale farmers, businessmen and employees. (aOR 2.9, 95\% C.I: 1.21$6.89, p<0.01$ ) (Table 3). Those respondents who came from Ngorongoro (pastoral communities) were 2 times more likely to test positive for anti-RVFV IgG as compared to respondents from other districts (aOR $1.8,95 \%$ C.I 1.14-3.39, $p=0.03$ ) (Table 3). Age, sex and level of education were statistically not associated with exposure to RVFV (Table 3).

The number of anti-RVFV IgG seroposivity was highest in Malambo, followed by Olbalbal, Nyerere (Serengeti) and Bunda health facilities. The seropositivity of IgM was determined from IgG seropositive samples only, and was sparsely distributed in Endulen, Piyaya, and Malambo in Ngorongoro district, as well as Bunda and Serengeti districts. Despite the higher anti-RVFV IgG seroprevalence in Olbalbal, no anti-RVFV IgM was detected (Fig. 1).

Table 1 Socio-demographic distribution of study respondents in the Serengeti ecosystem, 2014

\begin{tabular}{|c|c|c|c|c|}
\hline \multirow[b]{2}{*}{ Variable } & \multicolumn{3}{|l|}{ District } & \multirow{2}{*}{$\begin{array}{l}\text { Enrolled } \\
\text { Total } 751(\%)\end{array}$} \\
\hline & Bunda N = $300(\%)$ & Ngorongoro $N=210(\%)$ & Serengeti $N=241(\%)$ & \\
\hline \multicolumn{5}{|l|}{ Age group } \\
\hline$<15$ & $2(1)$ & $16(8)$ & $24(11)$ & $42(5.6)$ \\
\hline $15-29$ & $67(22)$ & $97(46)$ & $54(22)$ & $218(29.0)$ \\
\hline $30-49$ & $169(56)$ & $74(35)$ & $141(66)$ & $384(51.0)$ \\
\hline$>50$ & $62(21)$ & $23(11)$ & $22(9)$ & $107(14.3)$ \\
\hline \multicolumn{5}{|l|}{ Sex } \\
\hline Female & $186(62)$ & $132(63)$ & $121(50)$ & $439(58.5)$ \\
\hline Male & $114(38)$ & $78(37)$ & $120(50)$ & $312(41.5)$ \\
\hline \multicolumn{5}{|l|}{ Education Level } \\
\hline No Education & $15(5)$ & $97(46)$ & $98(41)$ & $214(28.5)$ \\
\hline Primary & $235(78)$ & $84(40)$ & $105(44)$ & $420(55.9)$ \\
\hline Secondary & $48(16)$ & $22(11)$ & $28(12)$ & $98(13.1)$ \\
\hline College & $2(7)$ & $7(3)$ & $10(4)$ & $19(2.5)$ \\
\hline \multicolumn{5}{|l|}{ Occupation } \\
\hline Businessmen & $31(10)$ & $10(5)$ & $29(12)$ & $70(9.3)$ \\
\hline Pastoralist & $17(6)$ & $150(71)$ & $59(25)$ & $227(30.2)$ \\
\hline Peasant & $217(72 \%)$ & $20(10)$ & $57(24)$ & $294(39.2)$ \\
\hline Employed & $15(5)$ & $19(9)$ & $15(6)$ & $49(6.5)$ \\
\hline Unspecified $^{\mathrm{a}}$ & $20(7)$ & $11(5)$ & 81 (34) & $112(15)$ \\
\hline
\end{tabular}

${ }^{a}$ Those whose occupation was not specified during data collection 
Table 2 Seroprevalence of anti-RVFV IgG by demographic factors in the Serengeti ecosystem, 2014

\begin{tabular}{|c|c|c|c|c|}
\hline Variable & No. Enrolled & No. of IgG + VE & Seroprevalence (\%) & $P$ value \\
\hline Total & 751 & 34 & 4.5 & \\
\hline \multicolumn{5}{|l|}{ Age group } \\
\hline$<15$ & 42 & 0 & 0 & 0.96 \\
\hline $30-49$ & 384 & 16 & 4.2 & 0.61 \\
\hline$>50$ & 107 & 7 & 6.6 & 0.57 \\
\hline $15-29$ & 218 & 11 & 4.4 & $\operatorname{Ref}^{* * *}$ \\
\hline \multicolumn{5}{|l|}{ Sex } \\
\hline Female & 439 & 17 & 3.9 & 0.30 \\
\hline Male & 312 & 17 & 5.5 & \\
\hline \multicolumn{5}{|l|}{ District } \\
\hline Bunda & 300 & 12 & 4.0 & 0.61 \\
\hline Ngorongoro & 210 & 17 & 8.1 & 0.003 \\
\hline Serengeti & 241 & 5 & 2.1 & Ref \\
\hline \multicolumn{5}{|c|}{ Level of education } \\
\hline Informal & 214 & 10 & 8.3 & 0.86 \\
\hline Primary & 420 & 18 & 4.3 & 0.996 \\
\hline Secondary ${ }^{b}$ & 117 & 5 & 4.3 & Ref \\
\hline \multicolumn{5}{|l|}{ Occupation } \\
\hline Businessman & 70 & 4 & 5.7 & 0.36 \\
\hline Pastoralist & 227 & 20 & 8.8 & 0.008 \\
\hline Others $^{\mathrm{a}}$ & 111 & 0 & 0 & - \\
\hline Employed & 49 & 0 & 0 & - \\
\hline Peasant & 294 & 10 & 3.4 & Ref \\
\hline
\end{tabular}

${ }^{\text {a }}$ Those whose occupation was not specified during data collection

${ }^{b}$ Secondary include both with secondary and college education

***Ref- Reference group in Epi info

\section{Discussion}

This study has shown past and recent exposure to RVFV in the Serengeti ecosystem, as both anti-RVFV IgG and IgM were detected. Anti-RVFV IgG antibodies are believed to last decades after infection and so provide a reliable index of prior RVF exposure. In contrast, anti-RVFV IgM has been reported to persist for only 6 to 8 weeks after initial infection [15]. Thus, finding anti-RVFV IgM antibodies does suggest recent exposure to the RVF infection among humans residing in the Serengeti ecosystem during interepidemic period. Living in Ngorongoro and being a pastoralist were the two common risk factors associated with exposure to RVF infection in our study.

The overall seroprevalence (4.5\%) of RVF in the Serengeti ecosystem was slightly higher than (4\%) previously reported in Tanga before the 2006/7 outbreak [17]. The slight increase of prevalence in this study might be because of cumulative exposure to RVFV infection in humans. Detection of anti-RVFV IgM among IgG seropositive humans was evidence that there is ongoing transmission of infection among humans during the interepidemic period. Lack of clinical RVF cases among anti-RVFV IgM positive humans might be due to the fact that the infections were sub-clinical or they were being missed or misdiagnosed for other disease conditions at health facilities, and this needs more studies. The ongoing transmission may be facilitated by the presence of several species of mosquitoes capable of spreading the disease $[18,19]$. Some of these mosquitoes have been shown to be infected with RVFV in sister study to this (Nyarobi unpublished). In addition, eating raw animal products, including meat, blood and unpasteurised milk is a common practice among community members living in the study area $[17,20]$. The detection might also be due to exposure to infected animals and wildlife in the area. The recorded anti-RVFV IgM seropositivity among anti-RVFV IgG reactive samples which were (17.6\%) in this study, was low compared to that of $(23 \%)$ recorded in study done shortly after 2006 outbreak [17]. However, there are several studies that didn't find any anti-RVFV IgM seropositive individuals in spite of presence of anti-RVFV IgG seropositive in both human $[18,21]$ and other vertebrate samples [5]. A large sample size may be 
Table 3 Socio-demographic factors associated with RVFV seropositivity in the Serengeti ecosystem, 2014

\begin{tabular}{|c|c|c|c|c|}
\hline \multirow[b]{2}{*}{ Risk Factor } & \multicolumn{2}{|c|}{ Outcome } & \multirow[b]{2}{*}{ cOR $(95 \%$ Cl) } & \multirow[b]{2}{*}{ aOR $(95 \% \mathrm{Cl})$} \\
\hline & +ve & $\overline{-v e}$ & & \\
\hline \multicolumn{5}{|l|}{ Occupation } \\
\hline Pastoralist & 20 & 205 & $3.56(1.77-7.19$ & $2.9(1.21-6.89)$ \\
\hline Others $^{a}$ & 14 & 512 & $\operatorname{Ref}^{*}$ & $\operatorname{Ref}^{*}$ \\
\hline \multicolumn{5}{|l|}{ District } \\
\hline Ngorongoro & 17 & 193 & $2.71(1.36-5.42)$ & $1.8(1.14-3.39)$ \\
\hline Others & 17 & 524 & $\operatorname{Ref}^{*}$ & $\operatorname{Ref}^{*}$ \\
\hline \multicolumn{5}{|l|}{ Education } \\
\hline High education & 5 & 93 & $1.15(0.44-3.06)$ & N/A \\
\hline Low education & 29 & 624 & $\operatorname{Ref}^{*}$ & \\
\hline \multicolumn{5}{|l|}{ Age group } \\
\hline$<29$ & 11 & 249 & $0.91(0.44-1.89)$ & N/A \\
\hline $30+$ & 21 & 470 & Ref & \\
\hline \multicolumn{5}{|l|}{ Sex } \\
\hline Male & 17 & 295 & $1.43(0.72-2.86)$ & $1.5(0.75-3.03)$ \\
\hline Female & 17 & 422 & $\operatorname{Ref}^{*}$ & $\operatorname{Ref}^{*}$ \\
\hline
\end{tabular}

${ }^{\mathrm{a}}$ All other occupational groups combined

Ref* - Reference group

useful to detect presence of IgM against the disease during interepidemic period especially in humans.

The evidence of spatial distribution of cases in this study shows that Ngorongoro district had higher seroprevalence, especially in Malambo, Olbabal and Piyaya wards, all of which are typical pastoral communities. In Bunda and Serengeti, most of the seropositive individuals were found from people residing mostly where pastoral and agro-pastoral activities take place, while in Ngorongoro, cases were from typical pastoral communities. The findings is in line with previous studies, where number of clusters of RVF cases was found in several parts of Ngorongoro but neither in Bunda nor in Serengeti [8]. However, further research is needed to find out the reason behind this. It might be because of uncontrolled movement of live animals and animal products from Ngorongoro, although data on livestock movement is very scarce [8]. Some of the seropositive individuals in Bunda DDH were coming from the Lamadi ward in Busega district, which is bordering Bunda district, and near to where RVF virus nucleic acids was recently detected in competent vector mosquitoes by Nyarobi, (unpublished).

Geographically, Ngorongoro district had the highest seroprevalence of anti-RVFV IgG compared to Bunda and Serengeti districts. The large area of Ngorongoro district is sparsely populated and livestock keeping is the main activity of the residents, as no cultivation is allowed in the area. The higher exposure rate in Ngorongoro district could be attributed by the 2006/07 RVF outbreak [6]. High rainfall, high temperature and soil texture supportive of flooding in Malambo ward in Ngorongoro, and high animal density in the ecosystem may account for high disease prevalence in Ngorongoro district [8]. It is known that Rift Valley fever virus once introduced in the area, continues to exist for decades as it is maintained by Aedes mosquitoes through vertical transmission [22]. Thus effective surveillance should be enhanced in order to detect cases as early as possible as well as prediction of future outbreaks using satellite mapping. Likewise, community members should be informed on the current disease status, so that residents can be motivated to adhere with preventive measures in order to keep themselves safe from contracting the disease.

In this study, pastoralists were more exposed to RVFV with anti-RVFV IgG seroprevalence of $8.9 \%$ compared to other occupations $3.0 \%$, which is in line with findings of other studies [23, 24]. This findings may be due to occupationally related risk of exposure exacerbated by high contact to infected animals and consumption of raw animal products such as blood, meat and milk [9]. Increased exposure might be enhanced because of poor community knowledge; attitude and practices related to RVFV infection and transmission pathways. For example, Maasai are used to keep their animals indoors during night to prevent them from wild carnivores' attacks [20]. This practice increases the frequency of contact to animals and hence potential for animal-human transmission during outbreak.

The study was done in the Serengeti ecosystem, where several outbreaks of Rift Valley Fever have been reported previously $[6,7]$. Thus the findings cannot be extrapolated to the entire country and may have limitation in generalization to other area of Tanzania. Likewise, as the study was cross-sectional in nature, it can only determine relationship at point in time and hence cannot determine temporal relationship. The study was designed as hospital-based study because of time limitation and financial constraints. The findings from this study can be used as an estimate of anti-RVF IgG and IgM seroprevalence in the Serengeti ecosystem, however, hospital-based study might have some bias and therefore it could be improved if it were supported by community survey.

Another potential limitation is not performing confirmatory virus neutralization test. However, comparison of IgG-sandwich and IgM-capture ELISA with virus neutralization test on field-collected sera from Africa $(n$ $=2400$ ) found the sensitivity of the IgG-sandwich ELISA was $100 \%$ and specificity $99.95 \%$, while for the IgM-capture ELISA the values were 96.47 and $99.44 \%$, respectively [19].

Following detection of anti-RVFV IgM, there is however, the need to conduct a study to determine the 
virulence of the viral strains circulating in the ecosystem. There might exist some strains, which are less virulent compared to the previous ones, or its virulence might have been altered by mutation due to lack of clinical cases during the study.

\section{Conclusion}

The study found both previous and recent exposure of RVFV in humans residing in the Serengeti ecosystem as antibodies against both IgG and IgM were detected. Detection of anti-RVFV IgM suggests an ongoing transmission of RVFV in humans during interepidemic periods. Since recent exposure to the disease was found in this study, health care workers should consider RVF during their differential diagnosis of fever, especially for patients coming from pastoral communities, or those highly exposed to animals and raw animal products. Enhanced, well organized and effective surveillance system should be in place to detect cases as early as possible.

\section{Abbreviations}

aOR: Adjust odds ratio; DDH: District designated hospital; GDP: Gross domestic product; GPS: Global positioning system; LGCA: Loliondo game controlled area; MUHAS: Muhimbili University of Health and Allied Sciences; NCA: Ngorongoro conservation area; OPD: Outpatient Department; OR: Odds ratio; RVF: Rift valley fever; TFELTP: Tanzanian field epidemiology and laboratory management training programme

\section{Acknowledgements}

We acknowledge the Nelson Mandela African Institute of Science and Technology and National Health Laboratory Quality Assurance and Training Centre for permission to use their laboratory facilities for sample analysis. We would like to thank Dr. Moshiro Candida and Alfred Musekiwa for statistical support, and fellow residents and TFELP staff, Dorothy L Southern and Leonard Mboera for useful comments in this paper. Mr. Machoke is thanked for drawing a map for the study area. Mr. Mdaki is thanked for his participation in data collection and laboratory sample analysis.

\section{Funding}

This work was supported by funds from the Tanzanian Field Epidemiology and Laboratory Management Training Programme (TFELTP). The funding agency did not any way influence the design of the study. Further funder did have access to the data and its management.

\section{Availability of data and materials}

The data sets used in the analysis of this current study is readily available from the corresponding author and can be accessed upon reasonable request.

\section{Authors' contributions}

AA, JM, FR, KJ, MM conceived and designed the study; JM contributed to sample collection; JM performed laboratory work; JM, AA, FR, KJ, MM analysed and interpreted the data; $\mathrm{AA}, \mathrm{JM}, \mathrm{FR}, \mathrm{KJ}$ and $\mathrm{MM}$ drafted the manuscript While AA supervised the overall work; All authors read and approved the final manuscript.

\section{Ethics approval and consent to participate}

We obtained written informed consent from all study participants. For the case of children, Consent was obtained from the parents/guardians of children who participated in the study and assent was sought for those aged 7-17 years. The study was reviewed and approved by the Ethical Committee of Muhimbili University of Health and Allied Sciences (MUHAS). Authority to conduct the study was obtained from Tanzania Wildlife Research Institute, Commission for Science and Technology, Ngorongoro Conservation Area Authority, the respective District Councils for Bunda,
Ngorongoro, Serengeti and the Management of the respective health facilities.

\section{Competing interests}

The authors declare that they have no competing interests.

\section{Publisher's Note}

Springer Nature remains neutral with regard to jurisdictional claims in published maps and institutional affiliations.

\section{Author details}

${ }^{1}$ Tanzania Field Epidemiology and Laboratory Training Program, Ministry of Health, Community Development, Gender, Elderly and Children, P.O Box 71286, Ocean Road, Dar es Salaam, Tanzania. ${ }^{2}$ Department of Microbiology and Immunology, Muhimbili University of Health and Allied Science, Dar es Salaam, Tanzania. ${ }^{3}$ Tanzania Wildlife Research Institute, Arusha, Tanzania.

Received: 17 March 2017 Accepted: 3 June 2018

Published online: 14 June 2018

\section{References}

1. Caroline AL, Powell DS, Bethel LM, Oury TD, Reed DS, Hartman AL. Broad spectrum antiviral activity of favipiravir (T-705): protection from highly lethal inhalational Rift Valley fever. PLoS Negl Trop Dis. 2014 Apr;8(4):e2790.

2. Caminade C, Ndione JA, Diallo M, Macleod DA, Faye O. Rift Valley fever outbreaks in Mauritania and related environmental conditions. Int J Environ Res Public Health. 2014;1 1(10):903-18.

3. Kahlon SS, Peter CJ, LeDuc J, Muchiri EM, Muiruri S, Njenga MK, et al. Case report: severe rift valley fever may present with a characteristic clinical syndrome. Am J Trop Med Hyg. 2010;82(3):371-5.

4. Gerdes GH. Rift Valley fever The importance of Rift Valley fever for animal and public. Africa (Lond) [Internet] 2004;23(2):613-623. Available from: https://pdfs.semanticscholar.org/abe9/ 8850bbd310910b95830d6ceaa64ec42fdb23.pdf

5. Joshua G, Sallu R. Epidemiological study of Rift Valley fever virus in. Onderstepoort J Vet Res. 2014;8(2):2-6.

6. Labeaud AD, Cross PC, Getz WM, Glinka A, King CH. Rift Valley Fever Virus Infection in African Buffalo (Syncerus caffer) Herds in Rural South Africa : Evidence of Interepidemic Transmission. Am J Trop Med Hyg. 2011;84(4):641-6

7. Chiyo PI, Ng E. Spatio-temporal variation in prevalence of Rift Valley fever: a post- epidemic serum survey in cattle and wildlife in Kenya. Infect Ecol Epidemiol. 2015;1(2):1-8.

8. Mohamed M, Mosha F, Mghamba J, Zaki SR, Shieh WJ, Paweska J, et al. Epidemiologic and clinical aspects of a Rift Valley fever outbreak in humans in Tanzania, 2007. Am J Trop Med Hyg. 2010;83(2 SUPPL):22-7.

9. Fyumagwa RD, Ezekiel MJ, Nyaki A, Mdaki ML, Katale ZB. Response to Rift Valley fever in Tanzania: challenges and opportunities. Tanzan J Health Res. 2011;13(December):1-9.

10. Sindato C, Karimuribo ED, Pfeiffer DU, Mboera LEG, Kivaria F, Dautu G, et al. Spatial and temporal pattern of Rift Valley fever outbreaks in Tanzania; 1930 to 2007. Tanzania J Health Res. 2014;9(2):888-97.

11. Chengula AA, Mdegela RH, Kasanga CJ. Socio-economic impact of Rift Valley fever to pastoralists and agro pastoralists in Arusha, Manyara and Morogoro regions in Tanzania. Springerplus. 2013 Jan;2(1):549.

12. Sindato C, Karimuribo ED, Mboera LEG. The epidemiology and socioeconomic impact of Rift Valley fever epidemics in Tanzania: a review. Tanzan J Health Res. 2007; 1 (2):20-2.

13. Chipwaza B, Mugasa JP, Mayumana I, Amuri M, Makungu C, Gwakisa PS Community knowledge and attitudes and health workers' practices regarding non-malaria febrile illnesses in eastern Tanzania. PLoS Negl Trop Dis. 2014 May;8(5):28-96.

14. Fafetine J, Neves L, Thompson PN, Paweska JT, Rutten VPMG, Coetzer JAW. Serological evidence of Rift Valley fever virus circulation in sheep and goats in Zambézia Province, Mozambique. PLoS Negl Trop Dis. 2013;7(2):1-8.

15. Shieh $W-J$, Paddock CD, Lederman E, Rao CY, Gould LH, Mohamed M, et al. Pathologic studies on suspect animal and human cases of Rift Valley fever from an outbreak in eastern Africa, 2006-2007. Am J Trop Med Hyg. 2010 Aug;83(2 Suppl):38-42

16. Paweska JT, Burt FJ, Anthony F, Smith SJ, Grobbelaar AA, Croft JE, et al. IgGsandwich and IgM-capture enzyme-linked immunosorbent assay for the 
detection of antibody to Rift Valley fever virus in domestic ruminants. J Virol Methods. 2003 Nov;113(2):103-12.

17. Mwakatobe A, Nyahongo JW, Røskaft E. Livestock depredation by carnivores in the Serengeti ecosystem, Tanzania. Environ Nat Resour Res. 2013;3(4):46-57.

18. Sumaye RD, Geubbels E, Mbeyela E, Berkvens D. Inter-epidemic transmission of Rift Valley fever in livestock in the Kilombero River valley, Tanzania : a cross-survey. PLoS Negl Trop Dis. 2013;7(8):e2356.

19. Paweska JT, Felicity J, Burt RS. Validation of lgG-sandwich and lgM-capture ELISA for the detection of antibody to Rift Valley fever virus in humans. J Virol Methods. 124(1-2):173-81.

20. Swai ES, Choonman L. Prevalence of Rift Valley fever immunoglobulin $G$ antibody in various occupational groups before the 2007 outbreak in Tanzania. Vector-Borne Zoonotic Dis. 2009;9:579-82.

21. Mhina AD, Kasanga CJ, Sindato C, Karimuribo E, Mboera LEG. Rift Valley fever potential mosquito vectors and their infection status in Ngorongoro district in Northern Tanzania. Tanzan J Health Res. 2015;17(4):1-9.

22. Mweya CN, Kimera SI, Mellau LS, Mboera LE. Inter-epidemic abundance and distribution of potential mosquito vectors for Rift Valley fever virus in Ngorongoro district, Tanzania. Glob Health Action. 2015;8:25929.

23. Muiruri S, Sutherland LJ, Dahir S, Gildengorin G, Muchiri EM, Peters CJ, et al. Postepidemic analysis of Rift Valley fever virus transmission in northeastern Kenya: a village cohort study. Trop Med Int Heal. 2011;5(8):1420-9.

24. Nicholas DE, Jacobsen KH, Waters NM. Risk factors associated with human Rift Valley fever infection: systematic review and meta-analysis. Trop Med Int Health. 2014;19(12):1420-9.

Ready to submit your research? Choose BMC and benefit from:

- fast, convenient online submission

- thorough peer review by experienced researchers in your field

- rapid publication on acceptance

- support for research data, including large and complex data types

- gold Open Access which fosters wider collaboration and increased citations

- maximum visibility for your research: over $100 \mathrm{M}$ website views per year 